\title{
Tips and tricks in the endoscopic management of a complex biliary stone in Billroth II gastrectomy
}

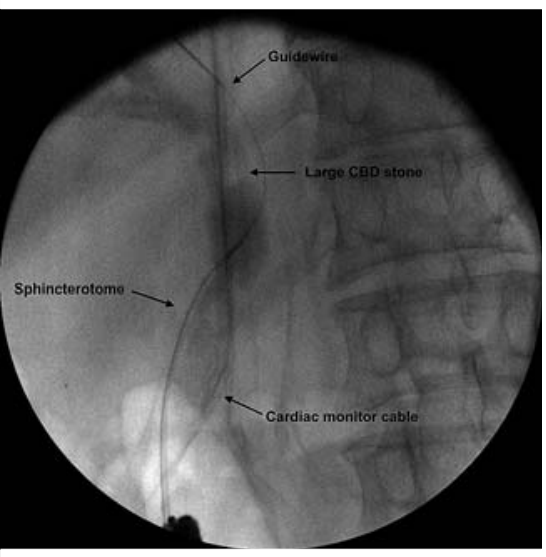

- Fig. 1 Fluoroscopic imaging showing correct biliary duct cannulation.

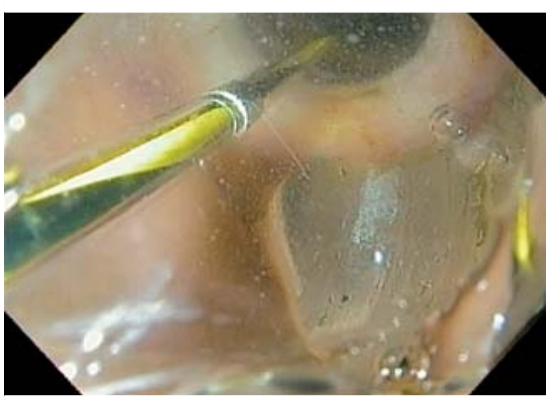

> Fig. 2 Endoscopic visualization of through-the-scope balloon during large hydrostatic balloon dilation.

Post-surgical anatomy may make traditional endoscopic retrograde cholangiopancreatography challenging for the endoscopist. In patients with Billroth II gastrectomy, challenges include selective entrance to the afferent loop and cannulation of the common bile duct (CBD) due to the inverted position [1]. Endoscopic management of CBD stones may be especially difficult in these patients, especially those with complex biliary stones [2].

We present a case of a 67-year-old gentleman with a previous Billroth II gastrectomy due to peptic ulcer disease who presented with jaundice (total bilirubin $9.72 \mathrm{mg} / \mathrm{dl}$, direct bilirubin $6.3 \mathrm{mg} / \mathrm{dl}$ )
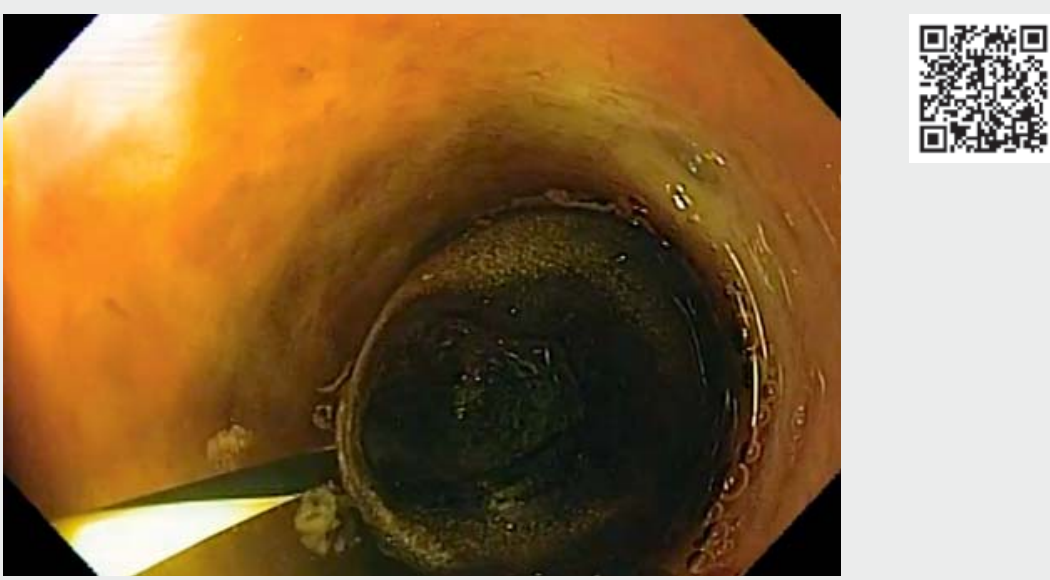

Video 1 Direct cholangioscopy as an alternative technique to treat complex biliary stones in Billroth II anatomy.
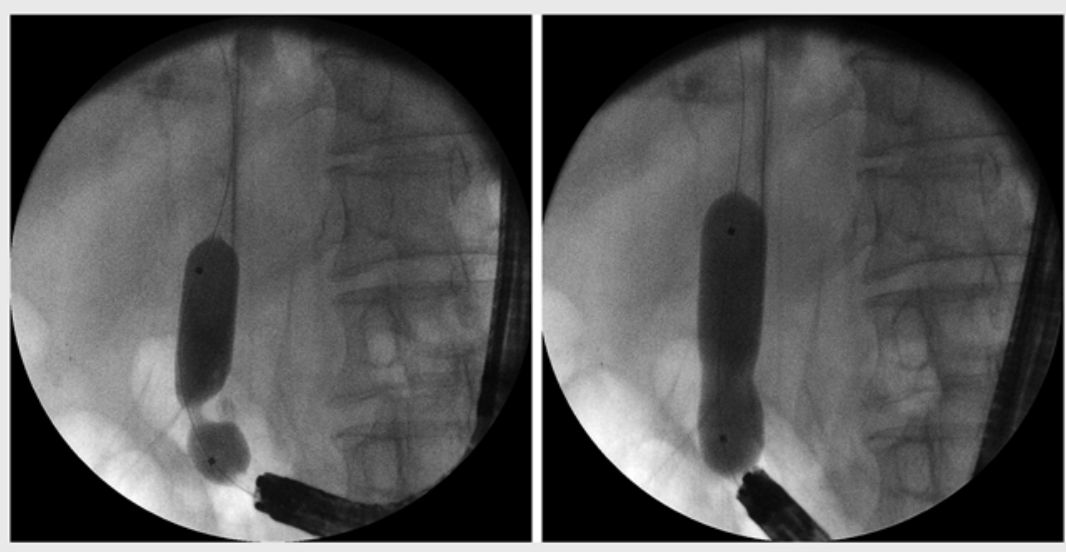

Dig. 3 Fluoroscopic imaging demonstrating the "radiological waist" and its disruption.

and abdominal pain. Imaging at this time with magnetic resonance cholangiopancreatography demonstrated extrahepatic bile duct dilation and a large distal CDB stone $(1.6 \mathrm{~cm} \times 1 \mathrm{~cm})$. For this case, a standard gastroscope was chosen in favor of a duodenoscope to decrease potential adverse events such as perforation [3].
On initial endoscopy, the major papilla was found and the cannulation occurred without difficulty ( Video 1, $>$ Fig.1). Fluoroscopy evaluation revealed a dilated CBD with a large biliary stone. The ideal position (5 o'clock) to perform sphincterotomy was not achieved. Therefore, a limited sphincterotomy was performed to guide the balloon dilation. Next, a large through-the-scope balloon dilation 


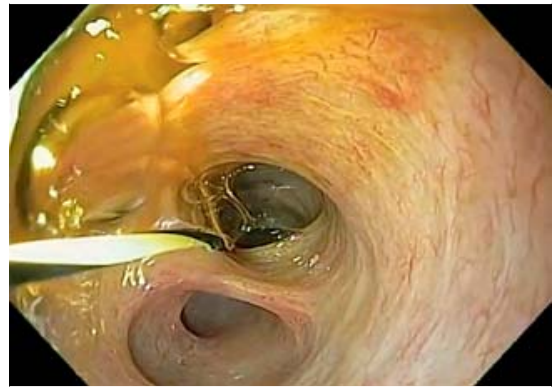

- Fig. 4 Final cholangioscopy demonstrated no residual stones.

(18 mm) was performed until disruption of the radiological "waist" ( - Fig. 3) [4]. Yet, despite several balloon sweeps, stone removal was unsuccessful. As a result, direct cholangioscopy with a standard gastroscope was then subsequently undertaken with the aim to improve the CBD axis and maximize traction force for stone extraction. The gastroscope was gently inserted into the ampulla and a large stone was visualized in the distal CBD. The stone was then removed using a balloon extraction technique without issue. Final cholangioscopy revealed no residual stones ( $\triangleright$ Fig.4). No adverse events occurred. In summary, alternative endoscopic techniques to treat difficult stones are feasible, safe, and effective when appropriately selected [5].

Endoscopy_UCTN_Code_TTT_1AR_2AH

\section{Competing interests}

The authors declare that they have no conflict of interest.
Guilherme Henrique Peixoto de Oliveira ${ }^{1}$, Diogo Turiani Hourneaux de Moura ${ }^{1} \stackrel{\oplus}{\text { Thomas }}$ R. McCarty ${ }^{2}$, Pedro Victor Aniz Gomes de Oliveira ${ }^{1}$, Mateus Pereira Funari ${ }^{1}$, Spencer Cheng ${ }^{1}$, Eduardo Guimarães Hourneaux de Moura ${ }^{1} \odot$

1 Gastrointestinal Endoscopy Unit, Gastroenterology Department, Hospital das Clínicas da Faculdade de Medicina da Universidade de São Paulo, Brazil

2 Gastroenterology, Hepatology and Endoscopy Division, Harvard Medical School, Brigham and Women's Hospital, Boston, Massachusetts, USA

\section{Corresponding author}

\section{Guilherme Henrique Peixoto de Oliveira,} MD

Av. Dr Enéas de Carvalho Aguiar, 225,

$6^{\circ}$ andar, bloco 3 , Cerqueira César, 05403-010 - São Paulo, SP, Brazil Fax: +55112661-6467 guilherme.hpoliveira@hc.fm.usp.br

\section{References}

[1] Manes G, Paspatis G, Aabakken L et al. Endoscopic management of common bile duct stones: European Society of Gastrointestinal Endoscopy (ESGE) guideline. Endoscopy 2019; 51: 472-491

[2] Bove $V$, Tringali A, Familiari P et al. ERCP in patients with prior Billroth II gastrectomy: report of 30 years' experience. Endoscopy 2015; 47: 611-616

[3] Byun JW, Kim JW, Sung SY et al. Usefulness of forward-viewing endoscope for endoscopic retrograde cholangiopancreatography in patients with Billroth II gastrectomy. Clin Endosc 2012; 45: 397-403
[4] de Clemente Junior CC, Bernardo WM, Franzini TP et al. Comparison between endoscopic sphincterotomy vs endoscopic sphincterotomy associated with balloon dilation for removal of bile duct stones: a systematic review and meta-analysis based on randomized controlled trials. World ] Gastrointest Endosc 2018; 16: 130-144

[5] Galetti F, Moura DTH, Ribeiro IB et al. Cholangioscopy-guided lithotripsy vs. conventional therapy for complex bile duct stones: a systematic review and meta-analysis. Arq Bras Cir Dig 2020; 33: 1491

Bibliography

Endoscopy 2022; 54: E338-E339

DOI 10.1055/a-1540-5956

ISSN 0013-726X

published online 19.7.2021

(c) 2021. Thieme. All rights reserved.

Georg Thieme Verlag KG, Rüdigerstraße 14, 70469 Stuttgart, Germany

\section{ENDOSCOPY E-VIDEOS}

https://eref.thieme.de/e-videos

口回 Endoscopy E-Videos is an open access online section, 自辞: reporting on interesting cases and new techniques in gastroenterological endoscopy. All papers include a high quality video and all contributions are freely accessible online. Processing charges apply (currently EUR 375), discounts and wavers acc. to HINARI are available.

This section has its own submission website at https://mc.manuscriptcentral.com/e-videos 